\title{
DISTANCE EDUCATION COMMUNICATIONS: THE SOCIAL PRESENCE AND MEDIA RICHNESS OF INSTANT MESSAGING
}

\author{
Stephen J. Kuyath \\ The William States Lee College of Engineering \\ University of North Carolina at Charlotte
}

Susan J. Winter

The Belk College of Business Administration

University of North Carolina at Charlotte

\begin{abstract}
Instant messaging (IM) is changing the way we communicate with each other and may prove to be a more effective communication tool for distance learning environments than the more commonly used discussion groups [1] and email. Media richness and social presence theories are described and young adults' perception of IM's richness and social presence are determined. In addition, preferences for using instant messaging for communicating messages of low, medium, and high levels of equivocality were investigated. The results indicate that young adults perceive IM to fall between email and the telephone in both social presence and media richness. As message equivocality increases, preference for the use of the telephone increases while preference for the use of email decreases. Preference for the use of IM increases for messages of intermediate equivocality, but decreases for those of high equivocality. Overall, young adults prefer IM over email as a communication tool, but prefer the phone over IM. Implications for media richness theory, social presence theory, and distance learning are described.
\end{abstract}

\section{KEYWORDS}

Social Presence, Media Richness, Instant Messaging, Distance Education

\section{INTRODUCTION}

The Internet is impacting the way Americans perform many tasks, including gathering information, making travel arrangements, paying bills, communicating with friends and relatives, and learning [1]. Because of the convenience and flexibility of anytime, anywhere learning for students in a distant education environment and the increased revenues for universities and colleges (due to increases in student enrollment) the Internet has sparked a renewed interest in distance education. The Internet provides the potential for new and creative ways to present information, provide resources, and answer questions for distance education students [1-9].

Despite the many years of experience with online distance education, there is still a debate surrounding its effectiveness. Researchers have studied the performance of distance education students compared to traditional classroom students [2, 4, 6, 7, 8], the value of multimedia [2, 5, 9], and the effectiveness of interactive communication techniques for course content delivery [5, 10-19]. The most consistent findings are that distance education students perform as well as or better than their traditional 
counterparts, but distance education students withdraw from classes at a higher rate than do the traditional students [20]. Two factors affecting the drop out rate for distance education students are their sense of social isolation and access to the instructor, both of which may be improved by incorporating IM into the distance education experience [10-14].

Distance learning has been found to be socially isolating, resulting in higher dropout rates and lower student satisfaction [10-14, 17]. A medium's ability to provide a sense that your communication partner is immediately available has been found to affect communication content, satisfaction, and the ability to communicate complex information [10-14, 17].

In addition to social distance, the problem of providing adequate student access to and interactions with the instructor is central to the debate regarding the effectiveness of distance education and its higher dropout rate. The quality of interactions with the instructor has been found to be the most significant contributor to the student's success in online distance education courses [15] and was rated as one of the two highest online-course quality indicators by students enrolled in distance education courses [10-14, 16].

Student satisfaction with an online course is tied to perceptions of the similarity or dissimilarity of online courses to traditional courses [10-14, 16] and Carnevale [20] found that distant students expect an instructor who interacts regularly with students just as they would in a traditional class. Students also expect a mechanism for discussions among students to facilitate building a community of learners in the class as would be found in traditional classroom environments [10-14, 20]. However, students in a distance education environment also expect to be working and interacting in a 24/7 environment and often find a delay in responses from other students or the instructor to be the most frustrating characteristic of online classes [10-14, 21].

Richardson and Swan [12, 17] found that instructor immediacy behaviors, such as responding instantly to emails, or returning phone calls immediately, not only affect student satisfaction with an online course, but also affect student learning outcomes $[12,17]$. The instructor's use of highly immediate behaviors has been associated with positive changes in students' attitudes that contribute to their success, including an elevated motivation to study and a perception that more was learned in the course $[12,17]$.

Faculty teaching online courses typically use web pages or email to post class announcements to their students and web-based discussion groups as the primary method for student-to-student communication or as the primary mode for instructor-student interactions [14]. However, these are not very immediate behaviors. Instant Messaging may be a communication method that is higher in social presence, simpler, richer, more immediate, and more effective than email or message boards for affecting the satisfaction and perceived learning of distant students [19, 20].

Although IM software may include Voice Over IP and document sharing applications, Shiu and Lenhart's [22] study of how IM is commonly used defines instant messaging as "a text-based tool that allows users to conduct conversations online by exchanging short messages in near synchronicity over the Internet” ( $p$ 1). IM users exchange IM screen names (identifiers) with friends to create a list of users (of the same instant messaging service) with whom they usually communicate, referred to as a "buddy list." When IM users log onto the service, they can immediately see who among their buddies are also logged on. The buddies who are logged onto the service are immediately notified of this new arrival to the service by an audio message. The users and their buddies can then exchange text messages in near synchronicity via the IM service. They may also use icons as avatars representing themselves to other users. Instant messaging 
Distance Education Communications: The Social Presence and Media Richness of Instant Messaging

has become so popular that it is now also available through many cell phone services and PDAs (personal digital assistants).

Forty-two percent of Internet users under the age of 27, approximately 53 million Americans, report using an IM Service to communicate with friends and family [22]. Mingail [23] reports that 132 million individuals worldwide (mostly teenagers) are now using IM and the number is predicted to grow to 300 million by the end of 2005. Shiu and Lenhart's [22] study of Internet users discovered that sixty-two percent of those using IM are under the age of 27 and it is predicted that in the near future, instant messaging will be used more often than email to communicate with others [24]. Clearly, instant messaging is a popular communication tool among the young adults typically targeted for distance learning in high school and college classes. As this cohort ages and IM diffuses into the larger population, it may become increasingly popular with older students and employees as well.

Miranda and Saunders [25] describe text-based computer mediated communications as being low in social presence, but this may not hold true for instant messaging. Due to IM's near synchronicity, participants can more easily focus on a conversation than they could when using email [10, 14]. Synchronicity could raise the perceived social presence of IM, making it a more effective communication tool for distance education and help in overcoming the social isolation felt by many participants [10, 14, 18].

Instant messaging's popularity among young adults may not establish that it can be an effective communication tool in distance education. It may only be appropriate for short and simple messages, which are a relatively trivial portion of distance education communications. The first step in establishing that IM can be a more effective communication medium than that currently used in distance education would be to determine if it could be used for communicating difficult, complex, or equivocal information. The theory of media richness and social presence provide a framework for this endeavor.

Based on their features, media richness theory has ranked various media according to their ability to reduce message equivocality [18]. Communicators then match the richness of the media to the equivocality of the message [20]. Communication media lower on the media richness scale are considered lean media and may not be effective for communicating messages of medium or high equivocality [20, 26], but are usually less costly in time or money. Lean communications media, such as written documents and email, are effective for routine messages of low equivocality (such as class announcements). As the content of a message becomes increasingly equivocal a richer communication media than written documents and email, such as face-to-face or telephone, is required; but this is not always possible with distant students [18, 19, 25, 26, 27]. A richer medium is needed for communications of higher equivocality, such as explaining a difficult concept to a distant student [20, 26]. Being text-based, IM would normally be considered a lean communication media [20, 26]. However, IM has features that may place it higher on the media richness scale than other forms of text-based media, and therefore make it useful for communications of higher equivocality.

In summary, instant messaging may provide the means to communicate complex information more effectively than email, making it a useful alternative for corresponding with distant students because it is both richer and has greater social presence. Although instant messaging is a text-based communication media, it has features that may place it higher than email on both the media richness and social presence scale. This study provides some insight into how young adults perceive the richness and social presence of instant messaging and shows how young adults rate the effectiveness of email, IM, and telephone for communicating information that varies in equivocality. It addresses the research question: Can instant 
messaging be used to communicate the equivocal information and create the social presence required for it to be an effective communication medium for distant students in an online education environment?

In the following section we will provide background information about social presence and media richness. Section three will describe the methods used in this study. The results are shown in section four followed by a discussion of the results in section five. In section six we highlight the implications of these results for theory and practice followed by a description of the limitations of this study. We close this paper with suggestions for future research concerning the use of instant messaging as an effective communication medium in distance learning.

\section{BACKGROUND AND HYPOTHESES}

\section{A. Social Presence}

Social presence has been variously defined as "the extent to which one feels the presence of a person with whom one is interacting" [6, p 559], and "the feeling one has that the other persons are involved in a communication exchange" [20, p 188]. Walther argues that the degree of social presence is determined by the communication medium and that the more channels or cues available in the medium, the more attention paid to the other participants in the communication [28]. Different forms of communication media offer different levels of social presence. Face-to-face communication is able to transmit facial expressions, body language, gestures, proximity, and non-verbal cues and is therefore the highest in social presence. Typical text-based communication media, such as email, are unable to provide non-verbal and visual cues and are, as a result, lower in social presence (see Figure 1).

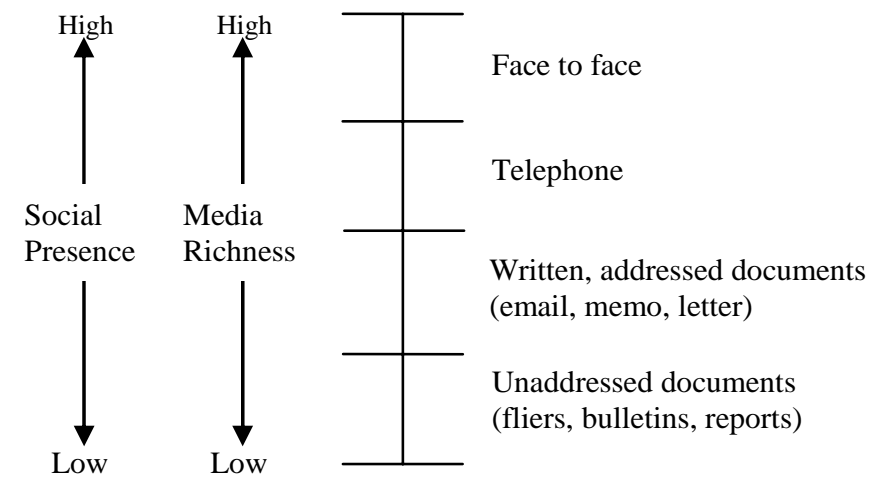

Figure 1: Media Richness and Social Presence Scales (adapted from [27] reproduced by permission from MIS Quarterly)

Miranda and Saunders [25] suggest that paper-based and text-based electronic communications, such as email, are viewed as low in social presence, while face-to-face communication is high in social presence. Sproull and Kiesler [29] found that computer mediated communication was weak in conveying social presence, and so a person's self-absorption is increased and their awareness of others is reduced. This may hold true for other forms of text-based computer mediated communication, but it may not hold true for instant messaging. The immediacy of a communication medium plays a role in its social presence such that greater delays in the communication media can contribute to a lower social presence [10, 12 , 29]. IM may be perceived as being higher in social presence than other forms of text-based communication media because it takes place in real time, providing immediate feedback. 
Telephone use is considered to be higher in social presence than text-based computer mediated communication [25] when you can actually contact the intended recipient. Sproull and Kiesler [29] argue that the indication that a participant is present and available for correspondence increases the medium's social presence. Instant messaging allows a participant to determine if his/her contact is logged into the service, and if so, make instant contact [22]. This feature of instant messaging may increase its social presence as compared to email (another form of text-based communication media).

Thus, because of IM's near synchronicity, multiple cues, and personal focus, it will likely have a higher social presence than other forms of text-based communication media, and only slightly lower than the social presence of telephone (see Figure 2).

Hypothesis 1: Instant messaging will be perceived as higher than email on the features that create a strong social presence, but lower on those features than the telephone.

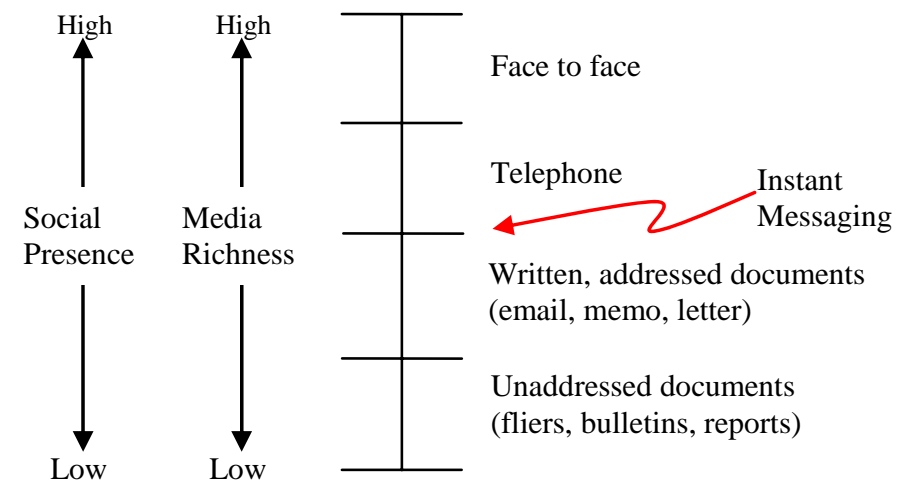

Figure 2: Hypothesized Location of IM on the Social Presence and Media Richness Scales

\section{B. Media Richness}

Media richness theory describes how various communication media carry both the intended information and the symbolic information with respect to the intended message and the sender [27]. The categories of communication media shown in Figure 1 differ in their capacity to transmit sufficient information to reduce, or completely remove, ambiguity in the message [27]. The communication media that are shown as higher in media richness are capable of reducing equivocality more efficiently than the leaner media. Daft et al. [27] contend that the features of a communication media-such as the capacity to allow quick feedback, provide multiple cues, use language variety, and the perception of personal focus-blend to determine the richness of the media [19, 26, 27].

Face-to-face is considered to be the richest form of communication because it offers the most channels for carrying information, such as facial expressions, body language, gestures, and auditory cues such as sighs, pauses, or vocal inflections [14, 19, 26, 27]. Because face-to-face communication is considered the richest media, all other communication media are compared to face-to-face, and in many ways are adapted or designed to be more like face-to-face communication. Where a medium cannot be adapted to be more like face-to-face communication people try to find ways to make up for the medium's lack of richness.

Instant messaging is a text based communication media and should therefore fall within the same range as the written, addressed documents on the media richness scale shown in Figure 1; however, instant messaging contains four other characteristics that may place it higher than other written, addressed 
documents on the media richness scale [27].

First, when two (or more) individuals are corresponding via IM, messages are received almost instantaneously. Their conversations are perceived to be occurring in near synchronicity [12, 18, 22, 26], providing an immediacy of feedback not available with other forms of written, addressed documents [12, $18,26,27]$.

Second, instant messaging provides multiple cues to the participants of a conversation. Audio cues occur when someone signs-on or signs-off of the instant messaging service, or when someone sends or receives a message [22]. As an example, when a person logs into the instant messaging service, all other users, who have listed him or her in their buddy list, hear an audio cue that sounds as if someone opened a door and walked into the room. Participants may also leave an away message to let someone know they are nearby, but have stepped away from the computer [19, 22, 26]. These multiple audio cues may place instant messaging higher than written, addressed documents on the media richness scale (see Figure 2). Similarly, the icon chosen as a participant's avatar can act as a cue to his or her personality or mood.

Language variety and personal focus also play a role in locating communication media along the media richness scale. Instant messaging allows a sender to easily place icons in a message to indicate feelings (in place of visual cues). Furthermore, IM users have developed a shorthand language to save time on typing and to allow participants to respond more quickly [22]. For example, instead of typing out "I have to go," IM users will type, "gtg” for "got to go", "gr8" for "great," or when the sender wants to indicate that they are making a joke, they will type "lol," for "laugh out loud."

Finally, the personal focus of communication participants is higher for IM than other forms of written, addressed documents due to the near synchronicity of message transmissions [19, 22]: participants are able to remain focused on the conversation and the other participants involved in the exchange.

The features of instant messaging, such as instant feedback, multiple cues, language variety, and personal focus, may place it higher than other forms of text-based communications media (such as email) on the media richness scale as shown in Figure 2. As the capacity of these characteristics of the media to transmit additional information increases, so will the perceived richness and the effectiveness of the communication media [18, 19, 27]. However, these features may remain insufficient to place IM higher than telephone or face-to-face communications. Telephone communications allow participants to transmit additional and more meaningful audio cues that are not available in IM (sighs, pauses, exclamations, etc.), and face-to-face allows non-verbal, visual cues, such as hand gestures, facial expressions, or other body language, in addition to the audio cues that are unavailable in IM.

Hypothesis 2: Instant messaging will be perceived as higher than email on the features that combine to create media richness, but lower than those of the telephone.

Research has also found that people are more likely to choose written documents for communication when the message to be conveyed is very clear $[18,19,27]$. As shown in Figure 3, richer forms of communication media, rather than the leaner forms of communication media, are more frequently chosen when the message contains a higher level of equivocality [27]. With the popularity of IM among young adults [22], it is assumed that they will choose to communicate via IM for messages of medium equivocality but will choose to use the telephone as equivocality increases and to use email for very clear messages. 


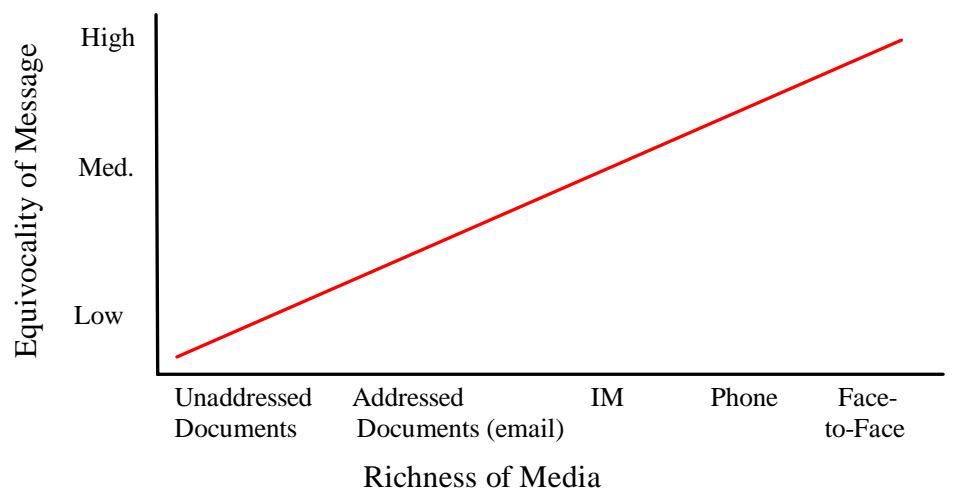

Figure 3: Media Choice: Richness of Media vs. Equivocality of the Message

Hypothesis 3a: Email will be the most preferred communication media for messages of low equivocality.

Hypothesis 3b: IM will be the most preferred communication media for messages of intermediate equivocality.

Hypothesis 3c: Telephone will be the most preferred communication media for messages of high equivocality.

\section{METHODS}

A survey was conducted to determine the levels of features associated with perceived social presence and perceived media richness for email, IM, and telephone (testing Hypotheses 1 and 2). To determine the media choice for transmission of information of low, intermediate, and high equivocality (Hypothesis 3 ) an experiment was performed.

\section{A. Participants}

The participants were randomly chosen from high school and college students between the ages of 18 and 24, participating in an unrelated event on a college campus in the southeast U.S. One hundred questionnaires were handed out; seventy-two questionnaires were returned for analysis, resulting in a $72 \%$ response rate. Over one third (37\%) of the event participants were female and $63 \%$ were male.

\section{B. Procedures}

Four assistants, each holding 25 surveys were asked to distribute the questionnaires randomly to both high school and college student participants. The participants were asked to rate each communication medium (email, IM, and telephone) on the dimensions of social presence and media richness and to rate each medium's effectiveness in communicating messages of varying levels of equivocality. Participants were asked to return the surveys when completed to an assistant stationed nearby.

\section{Refinement}

The initial questionnaire was pilot tested with a group of young adults, considered to be informants for the study. The informants consisted of ten young adults (5 females and 5 males) between the ages of 18 and 24. All informants were enrolled in high school or college and used IM, email, and telephone on a 
regular basis. The informants were asked to complete a first draft of the questionnaire and then discuss the results. The original questionnaire was worded in such a way that the informants chose one communication media (email, IM, or telephone) as most effective for each dimension of social presence, media richness, and effectiveness in communicating the messages of varying equivocality. This was not what was intended, and so the questionnaire was revised so that the informants rated the appropriateness of each communication medium for all items.

\section{Measures}

\section{Social Presence}

Participants rated email, IM, and the telephone's effectiveness on the three dimensions of social presence:

1. Ability to perceive the presence of the person with whom you are communicating

2. Perception that the person you are communicating with is engaged in the conversation

3. Privacy of the conversation

\section{Media Richness}

Participants rated email, IM, and the telephone's effectiveness on the four dimensions of media richness:

1. Ability to provide quick feedback

2. Ability to quickly provide additional information

3. Perception that the person you are communicating with is focused on the conversation

4. Ability to use a variety of language elements to convey additional meaning.

\section{Media Choice}

Brief descriptions of three communication situations were developed, representing different levels of equivocality of the information to be communicated:

1. Low Equivocality: You want to set up a time and place to meet the following Saturday.

2. Medium Equivocality: You have a math problem that you need help with. It is not very complicated, but you need some clarification.

3. High Equivocality: You have a math problem that you need help with. It is very complicated, and you need detailed help to complete it.

Participants rated the effectiveness of each of three communication media (telephone, instant messaging, and email) for all three situations.

All measures consisted of a single item rated on a Likert scale of 0 to 4 , with 0 indicating that the media was ineffective and 4 indicating that the media was very effective.

\section{RESULTS}

For each dimension of social presence and media richness and each level of equivocality for media choice, a repeated measures MANOVA was conducted to compare the respondents' means. When Mauchley's test indicated a violation of sphericity, the degrees of freedom for the F test were adjusted by multiplying them by Geisser-Greenhouse's epsilon [30] ). The mean scores, standard deviations, and overall results are shown in Table 1 below. Overall effect size is reported as eta-squared which represents 
the percent of variance accounted for. Planned contrasts tested the differences between pairs of means. For clarity, the results of these tests are discussed below, but are not shown in the table (t-values are available from the authors upon request).

\section{A. Elements of Social Presence}

Providing support for Hypothesis 1, five of the six planned comparisons between means were statistically significant at the .05 level or better and in the predicted direction. On every dimension of social presence, participants rated IM significantly higher than email indicating that they perceive IM to have a higher degree of social presence than email On two of the three dimensions of social presence, participants rated IM as significantly lower than the telephone, indicating that they perceive the person with whom they are communicating to be more focused on the conversation and more socially present when using a telephone than when they are using IM. Effect sizes for mean comparisons are shown in standard deviation units [31] and each represents the comparison of the mean with the one shown above.

Table 1: Results for Perceptions of Social Presence

\begin{tabular}{|c|c|c|c|c|}
\hline Levels of Equivocality & Mean & Std. Dev. & & Effect Size \\
\hline $\begin{array}{c}\text { Perception of Presence } \\
\text { Email } \\
\text { IM } \\
\text { Phone } \\
\text { Omnibus Test of Differences Among Means }\end{array}$ & $\begin{array}{l}1.64 \\
2.47 \\
3.11\end{array}$ & $\begin{array}{l}1.12 \\
0.92 \\
1.15\end{array}$ & $F_{(1.7,60.1)}=29.51^{* * *}$ & $\begin{array}{c}\mathrm{d}=.81 \\
\mathbf{d}=\mathbf{1 . 2 2} \\
\text { Eta-squared }=. \mathbf{3 7}\end{array}$ \\
\hline $\begin{array}{c}\text { Conversation Engagement } \\
\text { Email } \\
\text { IM } \\
\text { Phone } \\
\text { Omnibus Test of Differences Among Means }\end{array}$ & $\begin{array}{l}1.53 \\
2.54 \\
3.08\end{array}$ & $\begin{array}{l}1.15 \\
0.99 \\
1.15\end{array}$ & $F_{(1.7,58.9)} 35.24^{* * *}$ & $\begin{array}{c}\mathrm{d}=.94 \\
\mathrm{~d}=.51 \\
\text { Eta-squared }=.41\end{array}$ \\
\hline $\begin{array}{c}\text { Perception of Privacy } \\
\text { Email } \\
\text { IM } \\
\text { Phone } \\
\text { Omnibus Test of Differences Among Means }\end{array}$ & $\begin{array}{l}1.92 \\
2.50 \\
2.53\end{array}$ & $\begin{array}{l}1.33 \\
1.14 \\
1.33\end{array}$ & $F_{(1.8,62)} 6.40^{* *}$ & $\begin{array}{c}\mathrm{d}=.47 \\
\mathrm{~d}=.02 \\
\text { Eta-squared }=.17\end{array}$ \\
\hline
\end{tabular}

The dimension for which there was no significant difference between IM and the telephone was the perception of privacy. In both cases (IM and phone) participants rated the communication media to be fairly private. This may be an indication that young adults are unaware of the possibility that the user's Internet Service Provider can record IM transcripts, but they may realize that they can be eavesdropped on while communicating via IM or the telephone.

For the most part, the results support Hypothesis 1, that young adults perceive a higher degree of social presence when communicating via instant messaging than with email, but lower social presence when communicating via IM than telephone. 


\section{B. Dimensions of Media Richness}

Providing support for Hypothesis 2, seven of the eight planned comparisons between means were statistically significant at the .05 level or better and in the predicted direction (see Table 2). IM was rated significantly higher than email on all dimensions of media richness, indicating that the participants perceived IM to be a richer media than email. On three of the four dimensions of media richness, telephone was rated significantly higher than IM, indicating that the participants mostly perceived IM to be a less rich communication medium than the telephone.

Table 2: Results for the Dimensions of Media Richness

\begin{tabular}{|c|c|c|c|c|}
\hline Dimension & Mean & Std. Dev. & & Effect Size \\
\hline \multicolumn{5}{|l|}{ Immediacy of Feedback } \\
\hline Email & 1.90 & 1.08 & & \\
\hline IM & 2.76 & 1.04 & & $\mathrm{~d}=.81$ \\
\hline Phone & 3.04 & 1.01 & & $\mathrm{~d}=.27$ \\
\hline Omnibus Test of Differences Among Means & & & $F_{(2,70)} 20.58^{* * * *}$ & Eta-squared $=.34$ \\
\hline \multicolumn{5}{|l|}{ Capacity for Additional Information } \\
\hline Email & 2.03 & 1.03 & & \\
\hline IM & 2.36 & 0.95 & & $\mathrm{~d}=. \mathbf{3 3}$ \\
\hline Phone & 2.94 & 1.11 & & $\mathrm{~d}=.56$ \\
\hline Omnibus Test of Differences Among Means & & & $F_{(2,70)} 13.67^{* * *}$ & Eta-squared $=.24$ \\
\hline \multicolumn{5}{|l|}{ Participant Focused } \\
\hline Email & 1.85 & 1.24 & & \\
\hline IM & 2.29 & 0.99 & & $\mathrm{~d}=. \mathbf{3 9}$ \\
\hline Phone & 2.99 & 1.18 & & $d=.65$ \\
\hline Omnibus Test of Differences Among Means & & & $F_{(1.7,59)} 15.90^{* * *}$ & Eta-squared $=.24$ \\
\hline \multicolumn{5}{|l|}{ Language Variety } \\
\hline Email & 2.17 & 1.11 & & \\
\hline IM & 2.79 & 0.92 & & $\mathrm{~d}=.61$ \\
\hline Phone & 2.76 & 1.22 & & $\mathrm{~d}=.02$ \\
\hline Omnibus Test of Differences Among Means & & & $F_{(1.7,58)} 7.03^{* *}$ & Eta-squared $=.19$ \\
\hline
\end{tabular}

The one dimension on which the telephone and IM were not significantly different was language variety. This result came as somewhat of a surprise. During telephone conversations a variety of sounds, sighs, pauses, and vocal inflections may be used to transmit much more information than should be available in IM. But, the participants saw no significant difference between IM and telephone on this dimension of media richness. It is possible that the participants did not understand the term used in the questionnaire in the same way that media richness researchers use it. They may also have considered the many possible shorthand phrases commonly used to be varieties of language. Additional research will be required to better understand these surprising results. 


\section{Effectiveness for Different Levels of Equivocality}

Participants were asked to rate each of the communication media on its effectiveness in communicating information of varying levels of equivocality (low, medium and high). Table 3 displays the results used to determine if there was a significant difference in the participants' perceptions of each media's effectiveness.

Table 3: Results for Media Choice

\begin{tabular}{|c|c|c|c|c|}
\hline Levels of Equivocality & Mean & Std. Dev. & & Effect Size \\
\hline \multicolumn{5}{|l|}{ Low } \\
\hline Email & 2.21 & 1.15 & & \\
\hline IM & 2.53 & 1.06 & & $\mathrm{~d}=.29$ \\
\hline Phone & 2.83 & 0.92 & & $\mathrm{~d}=\mathbf{. 3 0}$ \\
\hline Omnibus Test of Differences Among Means & & & $F_{(1.7,59)} 5.76^{* *}$ & Eta-squared $=.14$ \\
\hline \multicolumn{5}{|l|}{ Medium } \\
\hline Email & 2.04 & 1.11 & & \\
\hline IM & 2.78 & 1.01 & & $\mathrm{~d}=.71$ \\
\hline Phone & 3.07 & 1.09 & & $\mathrm{~d}=.28$ \\
\hline \multicolumn{3}{|l|}{ Omnibus Test of Differences Among Means } & $F_{(1.8,64)} 16.21^{* * * *}$ & Eta-squared $=.26$ \\
\hline \multicolumn{5}{|l|}{ High } \\
\hline Email & 1.68 & 1.21 & & \\
\hline IM & 2.54 & 1.01 & & $d=.78$ \\
\hline Phone & 3.18 & 1.18 & & $\mathrm{~d}=.59$ \\
\hline Omnibus Test of Differences Among Means & & & $F_{(2,70)} 28.53^{* * *}$ & Eta-squared $=.41$ \\
\hline
\end{tabular}

To help visualize these results, the means were graphed and are displayed in Figure 4. 


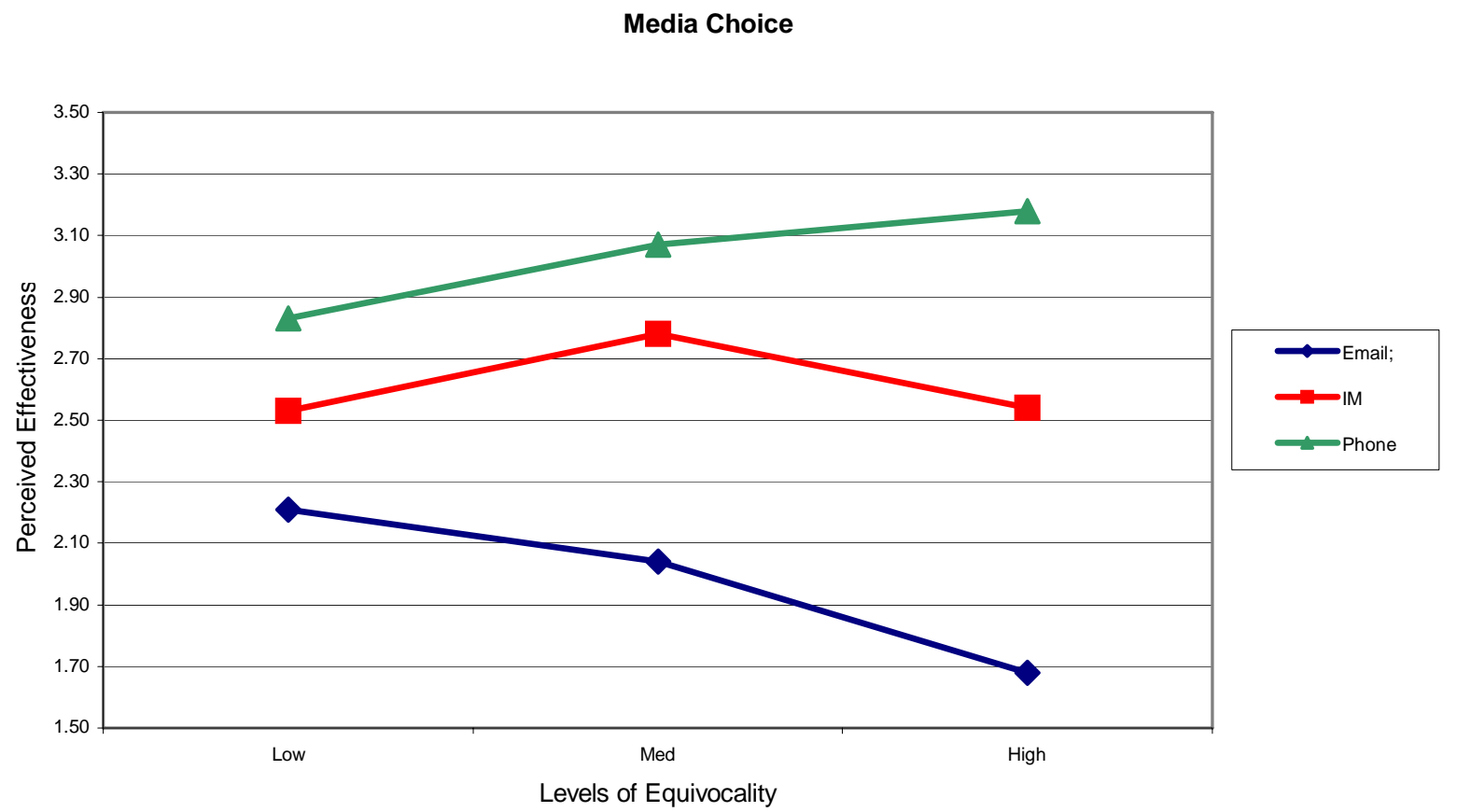

Figure 4: Levels of Equivocality vs. Perceived Effectiveness

For messages of all levels of equivocality, young adults considered the telephone most effective, followed by IM, and then by email (the most used medium for distance learning). Hypothesis 3a was not supported. Email was not considered the most effective medium for messages of low equivocality. Similarly, Hypothesis $3 \mathrm{~b}$ was not supported. IM was not considered the most effective medium for messages of intermediate equivocality. Hypothesis 3c was supported. The telephone was considered the most effective medium for messages of high equivocality. These results also show that, if IM were the only means of communication, young adults would perceive it as more effective when discussing topics with a medium level of equivocality than when discussing topics of a high or low level of equivocality.

\section{DISCUSSION}

Overall, young adults perceive instant messaging to be higher in social presence than email, but lower than the telephone. Instant messaging allows young adults to be more aware of another's presence, not only before making contact (they can see that their contact is logged into the system), but also while they are communicating (increasing the immediacy of feedback). This increases the social presence of instant messaging making it a more preferred medium than email for young adults. They see IM and the telephone as about equally private, but more private than email.

These results also place instant messaging between email and telephone on the media richness scale. Instant messaging allows users to communicate in near synchronicity over the Internet, providing an immediacy of feedback, allowing multiple cues, a more personal focus and more language variety. Young adults perceive these features to be higher in instant messaging than in email, but lower than that provided by the telephone (except for language variety which is seen as about the same as that provided by the telephone). These elements of instant messaging blend to place instant messaging higher on the media richness scale than email. 
Distance Education Communications: The Social Presence and Media Richness of Instant Messaging

Social presence and media richness theories predict that a person will choose a specific communications media based on the equivocality of the messages. As levels of equivocality rise, people considered communications media with higher social presence and greater media richness to be more effective. The results of this study showed an interesting relationship between media choice and message equivocality. As equivocality increased, the perceived effectiveness of email decreased and the perceived effectiveness of the telephone increased. The perceived effectiveness of IM showed a curvilinear relationship with equivocality. It was considered more effective for messages of intermediate equivocality than for those of low or high equivocality. However, for all levels of equivocality, the telephone was considered the most effective communication media while email was considered the least effective.

These results have clear implications for faculty teaching distance education courses. One of the concerns of most faculty and students participating in distance education courses is that distance education students do not receive the benefit of a close interaction with their peers and teachers. Most distant students are limited to email or discussion boards to ask questions or to communicate with their peers. Instant messaging could provide the perception that the faculty member or peer is close by and focused on their dialog and that the distant student is getting the personal attention that his on-campus counterpart receives. It can also improve the ability to effectively and accurately communicate the equivocal information that forms the most important part of the distance learning experience: student-teacher interaction when student questions arise.

Because young adults perceive instant messaging to be higher in social presence and media richness than email, it could also provide better-perceived access to the instructor. Distant students and their on-campus counterparts will never have equal access to their professors, but perhaps instant messaging could provide a medium for communication that will make the distant students' experience approach that of the traditional, on-campus student.

These results also have important implications for media richness theory, which predicts that leaner communication media will be chosen for conveying messages of low equivocality. However, our sample of young adults considered the telephone to be the most effective medium for conveying information at all levels of equivocality. Assuming that they would choose the medium that they considered most effective, these results contradict media richness theory. It is possible that perceptions of effectiveness reflect a social construction of reality, the prevailing norms of one's social group, or the users' affective response to using the medium, not its instrumental value.

\section{LIMITATIONS AND FUTURE RESEARCH}

There are several limitations to this study. First, our results are based on a relatively small sample of young adults. Second, the questionnaire relied on self-reports of perceived effectiveness. It is difficult to assess how accurately respondents reported their perceptions and whether these perceptions reflected the actual effectiveness of each medium in conveying messages with various levels of equivocality. Future research should establish the effectiveness of instant messaging in an actual distance-learning environment. Further, student reactions to the use of IM may depend not only on their perceptions of IM, but also on their perceptions of the instructor's use of the medium. Instructors may vary in their performance of immediacy behaviors with some being available through IM much more often and longer than others. Lastly, all the respondents were high achieving high school and college students participating in a math and science competition. 
Further studies should be conducted to extend our findings to young adults in other achievement domains and to older adults. Additional work will be required to better understand why so few instructors are currently using the IM features available in common teaching software packages. Finally, it is not clear if these results would be the same for students in all areas of study (e.g. engineering, business, drama).

\section{CONCLUSIONS}

Instant messaging is fairly new, and has already been shown to be a widely accepted and popular communication media for young adults. The use of instant messaging is predicted to grow and be used more often than email. This study has extended the literature on social presence and media richness to instant messaging. It has also established that young adults perceive the richness and social presence of instant messaging to be higher than that of email and lower than that of telephone. This study also confirmed which media younger adults preferred when attempting to communicate messages of low, medium, and high equivocality. The results suggest that young adults prefer instant messaging to email and find it richer and higher in social presence than email. It may also be the most cost effective method for improving distance education outcomes and reducing dropout rates.

\section{ACKNOWLEDGEMENTS}

We would like to thank M. Adeel Zaffar, Haya Alchaar, and Yuan Niu for their comments and suggestions on earlier versions of this paper.

\section{ABOUT THE AUTHORS}

Stephen J Kuyath is Assistant Professor in Engineering Technology at the College of Engineering of the University of North Carolina at Charlotte. Visit http://www.coe.uncc.edu/ sjkuyath/ for more information.

Susan J. Winter is in the Department of Business Information Systems and Operations Management, Belk College of Business Administration, University of North Carolina Charlotte, Charlotte, NC.

\section{REFERENCES}

1. Williamson, C., J. T. Bernhard and K. Chamberlin. Perspectives on an Internet-Based Synchronous Distance Learning Experience. Journal of Engineering Education 89(1): 53-61, 2000.

2. Daily, B. and M. Daily. Effectiveness of a Multimedia Televised Distance Education Program for Engineering Majors. Journal of Engineering Education 83(4): 1-5, 1994.

3. Boulet, M. M. and S. Boudreeault. Using Technology to Deliver Distance Education in Computer Science. Journal of Engineering Education 87(4): 433-436, 1998.

4. Dutton, J., M. Dutton and J. Perry. Do Online Students Perform as Well as Lecture Students? Journal of Engineering Education 90(1): 131-136, 2001.

5. Webster, T. J. and K. M. Haverstroh. An Interactive, Video-Teleconferenced, Graduate Course in Biomedical Engineering. Journal of Engineering Education 91(2): 159-166, 2002.

6. Latchman, H. A. and S. M. Latchman. Bringing the Classroom to Students Everywhere. Journal of Engineering Education 89(4): 429-433, 2000

7. Wallace, D. R. and P. Mutooni. A Comparative Evaluation of World Wide Web-Based and Classroom Teaching. Journal of Engineering Education 86(3): 211-219, 1997. 
Distance Education Communications: The Social Presence and Media Richness of Instant Messaging

8. Kadiyala, M. and B. L. Crynes. A Review of Literature on Effectiveness of Use of Information Technology in Education. Journal of Engineering Education 89(2): 177-189, 2000.

9. Burleson, W., A. Ganz and I. Harris. Educational Innovations in Multimedia Systems. Journal of Engineering Education 90(1): 21-31, 2001.

10. Swan, K. Virtual interactivity: design factors affecting student satisfaction and perceived learning in asynchronous online courses. Distance Education 22(2): 306-33, 2001.

11. Rourke, L., T. Anderson, D. R. Garrison and W. Archer. Assessing Social Presence In Asynchronous Text-based Computer Conferencing. Journal of Distance Education 5(2): 2001.

12. Swan, K. Immediacy, social presence, and asynchronous discussion. In J. Bourne and J. C. Moore (Eds.) Elements of Quality Online Education, Volume 3. Needham, MA: Sloan-C, 2002.

13. Swan, K. Learning online: current research on issues of interface, teaching presence and learner characteristics. In J. Bourne and J. C. Moore (Eds.) Elements of Quality Online Education, Into the Mainstream, 63-79. Needham, MA: Sloan-C, 2004.

14. Swan, K. and L. F. Shih. On The Nature And Development of Social Presence In Online Course Discussions. Journal of Asynchronous Learning Networks 9(3): 2005.

15. Fredricksen, E., A. Pickett, P. Shea, W. Pelz, and K. Swan. Student Satisfaction and Perceived Learning with OnLine Courses: Principles and Examples from the SUNY Learning Networks. Journal of Asynchronous Learning Networks 4(2): 7-41, 2000.

16. Cohen, M. S. and T. J. Ellis. Developing Criteria for an On-Line Learning Environment: From the Student and Faculty Perspectives. Journal of Engineering Education 93(2): 161-167, 2004

17. Richardson, J. C. and K. Swan, K. Examining Social Presence in Online Courses in Relation to Students' Perceived Learning and Satisfaction. Journal of Asynchronous Learning Networks 7(1): 68-88, February 2003.

18. Hung, Y. C., W. C. Kong, A. L. Chua and C. E. Hull. Reexamining Media Capacity Theories using Workplace Instant Messaging. Proceedings of the 39th Hawaii International Conference on System Sciences, 2006

19. Garrison, D. R., T. Anderson and W. Archer. Critical Inquiry in a Text-Based Environment: Computer Conferencing in Higher Education. The Internet and Higher Education 2(2-3): 87-105 2000.

20. Carnevale, D. Study Assesses What Participants Look for in High-Quality Online Courses. Chronicle of Higher Education 47(9): A46, 2000

21. Kubala, T. Addressing Student Needs: Teaching on the Internet. T.H.E. Journal 25(8): March 1998.

22. Shiu, $\mathbf{E}$ and Lenhart, A. How Americans use instant messaging. Pew Internet. 2005. http://www.pewinternet.org/pdfs/PIP_Instantmessage_Report.pdf.

23. Mingail, S. Instant Messaging: Next best thing since e-mail? Gartner: 2005. http://www.gartner.com.

24. Kirsner, S. IM is here. RU prepared? Ecosystem Magazine: 2005. http://www.darwinmag.com/ read/020102/ecosystem.html.

25. Miranda, S. M. and C. S. Saunders. The Social Construction of Meaning: An Alternative Perspective on Information Sharing. Information Systems Research 14(1): 87-106, 2003.

26. Cameron, A. F. and J. Webster. Unintended consequences of emerging communication technologies: Instant Messaging in the workplace. Computers in Human Behavior 21: 85-103, 2005.

27. Daft, R. L., R. H. Lengel and L. K. Trevino. Message Equivocality, Media Selection, and Manager Performance: Implications for Information Systems. MIS Quarterly 11(3): 355-366, September 1987.

28. Walther, J. Relational aspects of computer-mediated communication: Experimental observations over time. Organization Science 6: 189-203, 1995.

29. Sproull, L. and S. Kiesler. Reducing Social context cures: Electronic mail in organizational communication. Management Science. 32: 1492-1512, 1986.

30. Tabachnick, B. G. and L. S. Fidell. Using Multivariate Statistics ( $4^{\text {th }}$ Ed). Boston, MA: Allyn and Bacon, 2001.

31. Cohen, J., P. Cohen, S. G. West and L. S.Aiken. Applied Multiple Regression/Correlation Analysis for the Behavioral Sciences ( $3^{\text {rd }}$ Ed.). Mahwah, NJ: Lawrence Erlbaum, 2003. 